\title{
Blink patterns and lid-contact times in dry-eye and normal subjects
}

This article was published in the following Dove Press journal:

Clinical Ophthalmology

5 May 2014

Number of times this article has been viewed

\author{
George W Ousler 3rd' \\ Mark B Abelson ${ }^{1,2}$ \\ Patrick R Johnston' \\ John Rodriguez' \\ Keith Lane' \\ Lisa M Smith'
}

'Ora, Andover, MA, USA; ${ }^{2}$ Department of Ophthalmology, Harvard Medical

School, Boston, MA, USA

Correspondence: George W Ousler 3rd Ora, 300 Brickstone Square, Andover, MA 0I8I0, USA

Tel +l 9786858900

Email gousler@oraclinical.com
Purpose: To classify blinks in dry eye and normal subjects into six subtypes, and to define the blink rate and duration within each type of blink, as well as the total lid-contact time/minute.

Materials and methods: This was a single-centered, prospective, double-blind study of eleven dry-eye and ten normal subjects. Predefined subjects watched a video while blinks were recorded for 10 minutes. Partial blinks were classified by percentage closure of maximal palpebral fissure opening: $25 \%, 50 \%, 75 \%$. Complete blinks were characterized as full ( $>0$ seconds), extended ( $>0.1$ seconds), or superextended ( $>0.5$ seconds). The mean duration of each type of blink was determined and standardized per minute as total lid-contact time.

Results: Total blinks observed were 4,990 (1,414 normal, 3,756 dry eye): 1,809 (50.59\%) partial and 1,767 (49.41\%) complete blinks among dry-eye subjects versus $741(52.90 \%)$ partial and $673(47.60 \%)$ complete blinks among normal subjects. Only superextended blinks of $\geq 0.5$-second duration were significantly more frequent in dry-eye subjects than normals ( $2.3 \%$ versus $0.2 \%$, respectively; $P=0.023$ ). Total contact time was seven times higher in dry-eye subjects than normals $(0.565$ versus 0.080 seconds, respectively; $P<0.001)$. Isolating only extended blinks ( $>0.1$ second), the average contact time (seconds) was four times longer in dry-eye versus normal subjects ( 2.459 in dry eye, 0.575 in normals; $P=0.003$ ). Isolating only superextended blinks ( $>0.5$ seconds), average contact time was also significantly different (7.134 in dry eye, 1.589 in normals; $P<0.001$ ). The contact rate for all full closures was 6.4 times longer in dry-eye $(0.045$ versus $0.007, P<0.001)$ than normal subjects.

Conclusion: Dry-eye subjects spent $4.5 \%$ of a minute with their eyes closed, while normal subjects spent $0.7 \%$ of a minute with their eyes closed. Contact time might play a role in the visual function decay associated with increased blink rates.

Keywords: keratoconjunctivitis sicca, dysfunctional tear syndrome, interblink interval, blink rate, visual function, visual tasks, diagnostic model, eyelid closures, microsleeps

\section{Introduction}

Blink phenomena have been extensively studied in various contexts of disease, fatigue and alertness, and visual tasking. Thirty years ago, we first classified blinks as complete, partial, and squeeze, with abnormalities observed in relation to keratitis. ${ }^{1}$ The mechanical properties of blinking were studied extensively in the 1980 s by Doane and others..$^{2-4}$ Blink rates are known to decrease with tasks of increasing difficulty, ${ }^{5-8}$ as well as in states of fatigue ${ }^{9}$ and with time on task, ${ }^{10}$ findings that have prompted investigation into blink-tracking devices as a means of monitoring driver safety. ${ }^{10-12}$ In dry eye, blink may function as a compensator for a dysfunctional and unstable tear film, further worsening the negative consequences on visual function. Dry-eye subjects frequently complain of ocular fatigue ${ }^{13}$ and decreased visual performance related to their disease, ${ }^{14,15}$ and it is intriguing to speculate what role altered blink states have in both fatigue and dry eye.

We study blink and how it is affected by dry eye and visual task, and have recently reported on interblink intervals (IBIs) and their temporal and mathematical 
characteristics that can be used to differentiate dry-eye and normal subjects. ${ }^{16}$ We have also focused our attention on the varying patterns of blink, finding that the IBIs surrounding extended blink closures increase significantly in dry-eye subjects. ${ }^{17}$ While absolute blink rates have been well studied in dry eye, ${ }^{18-22}$ we focused on exploring blink patterns and how individuals with dry eye may differ in their ability to modulate these patterns successfully to maintain optimal visual tasking.

Blinks have been defined in various ways, depending on the field of study, including kinematic properties (eg, duration) and associated neural activity, ${ }^{4,23}$ reflex, voluntary, endogenous, and conditioned responses, ${ }^{24}$ and nonblink closures. ${ }^{25}$ More recently, spontaneous eyeblink activity and its neural control have been studied independently of disease. ${ }^{26,27}$ So-called "squeeze blinks" are long-duration lid closures accompanied by elevated pressure on the lid margin. These have been shown to increase lipid expression ${ }^{28}$ and increase tear-film thickness. ${ }^{29}$ Eyelid closures of long duration may result from such factors as fatigue, and are often described as microsleeps, although they may occur in non-sleep-deprived normal subjects during work hours and may or may not be confirmed by electroencephalogram activity indicating actual sleep. ${ }^{30}$ In Stern's thorough review, ${ }^{9}$ a gamut of blink end points are presented and compared, such as amplitude, within-subject analysis of variance, duration of closure, catch-up blinks, and frequency and duration of flurries.

In normal and dry-eye subjects, we have observed eyelid closures of up to multiple seconds that we refer to as "extended blinks." In a previous study, we identified the number and duration of extended lid closures in dry-eye and normal subjects, and the unique nature of the IBI surrounding these long closures. ${ }^{17}$ Our specific parameter of interest in the present paper is mean lid-closure duration per type of blink and rate/minute of eyes closed. Increased blink rates do not always result in increased contact times because of the many erratic patterns of blink. Previously described blink phenomena, such as incomplete blinks, ${ }^{1,4,6,7,9}$ flurries (series of blinks occurring within a 3 -second window), ${ }^{9}$ volleys (flurries after periods of blink inhibition), ${ }^{6,9}$ and catch-up blinks (after periods of visual demand), ${ }^{6,9}$ all have greatly varying durations, leading to widely different lid-contact times with any given blink rate. A typical full blink can vary in duration from less than $10 \mathrm{~ms}$ to $80 \mathrm{~ms},{ }^{10,11}$ and thus a blink rate of 20 blinks per minute might have lid-contact times varying from $400 \mathrm{~ms}$ to $1,600 \mathrm{~ms}$. We investigated further into this concept of total lid-contact time as another possible key difference between dry eye and normals, and determined this measure for all blinks observed in a given time period. This "total time down", or time spent per minute with eyes closed, might be the clearest indicator of how dry eye can interfere with visual function. We also identified the gamut of blink patterns per subject and time period, exploring the possibility that the distribution of partial/complete closures and the average duration of blinks in each class might differ between dry-eye and normal subjects.

\section{Materials and methods}

This was the last in a series of three investigations ${ }^{16,17}$ carried out as single-center pilot studies designed to evaluate blink in a third series of ten normal and eleven dry-eye subjects. The study was conducted according to a protocol approved by an external independent review board (Alpha IRB, San Clemente, CA, USA), and written informed consent was obtained prior to study procedures.

\section{Subjects}

All subjects were at least 18 years of age and were required to have a best-corrected visual acuity of +0.6 logarithm of the maximum angle of resolution or better in each eye based on the Early Treatment of Diabetic Retinopathy Study (ETDRS) chart. Normal subjects had to have a negative history of dry eye and no reported dry-eye symptoms and a corneal fluorescein staining score of $<1$ on the Ora Calibra ${ }^{\mathrm{TM}}$ (Ora, Andover, MA, USA) scale of $0-4(0=$ none, $4=$ most severe $)$. Dry-eye subjects were required to meet all the following inclusion criteria: a previous diagnosis of dry eye, a desire to use or use of tear substitutes within the previous 6 months for relief of symptoms, abnormal fluorescein staining of the cornea (score of $\geq 1.5$ ), and a tear-film breakup time of $\leq 5$ seconds in at least one eye.

All subjects were required to avoid ophthalmic medications for 2 hours prior to the study visit. Subjects who had taken any systemic medications known to cause ocular drying were excluded from the study. Subjects were also excluded if they wore contact lenses, had a history of ocular surgery within the previous 12 months, had any ocular inflammation, allergy, or infection, or had any illness that could have confounded the study results.

\section{Video-monitoring environment}

We used our standardized method of video monitoring for blink assessments, as reported previously. ${ }^{16,17}$ Each subject individually viewed a 10-minute documentary displayed on a 25 -inch $(63.5 \mathrm{~cm})$ television from a viewing distance of 5 feet $(1.52 \mathrm{~m})$, in an isolated, well-lit room. Temperature and humidity were not controlled, but were 
within a comfortable range of $70^{\circ} \mathrm{F}-75^{\circ} \mathrm{F}\left(21.1^{\circ} \mathrm{C}-23.89^{\circ} \mathrm{C}\right)$ and $35 \%-55 \%$ relative humidity.

\section{Blink analysis}

To minimize forced blinking and other changes in natural blink patterns, the subjects were not told that blink patterns were being analyzed. The camera was mounted to a headset and directed toward the eye so that eyelid movement could be captured noninvasively. Postcapture, the videos were manually processed and blink patterns analyzed over the course of the 10-minute documentary-viewing period.

Partial blinks were classified by percentage closure of maximal palpebral fissure opening: $25 \%, 50 \%$, and $75 \%$. Complete blinks were characterized as any lid closures (all three classes of full blinks), all extended lid closures (greater than 0.1 second), and superextended lid closures only (greater than 0.5 second). The total lid-contact time was then determined for each blink-closure type, and the mean duration of each closure was calculated. This was then standardized per minute to calculate the mean contact rate for each type of closure in dry-eye and normal subjects.

Two sets of results are presented. The first analysis includes all blink data. The second set of results excludes seven superextended blinks with anomalous lid-closure duration times longer than ten seconds. These outlying lid closures appeared to be microsleeps or a conscious closing and resting of eyes during the observation period, and could not be defined as blink.

\section{Statistical analyses}

Frequencies of blink types (partial closures, full closures, and subtypes of each) were calculated as absolute counts and percentages. Data were fitted to repeated-measurement logistic models estimated by generalized estimating equation methods using the Genmod procedure of SAS 9.3 (SAS Institute, Cary, NC, USA). Standard errors were calculated using the robust (sandwich) method based on an exchangeable correlation structure. The dry-eye and normal groups were compared via odds ratios, and corresponding estimates, 95\% confidence intervals, and $P$-values for the two-sided test of equal odds were calculated.

\section{Results}

The outcomes measured in this study were total blink number and proportion of each blink type, total blink rate per minute, the incidence of full, extended, and superextended blinks, mean duration of blink in seconds within each category of blink, and mean lid-contact time per minute or lid-contact rate. Note that the category "all full closures" encompassed all blinks of any duration: 0 to over 10 seconds; the category of "extended blinks" encompassed all blinks of greater than 0.1 to over 10 seconds, and the category of "superextended blinks" encompassed all blinks over 0.5 seconds.

\section{Total blink number and proportions within each blink type}

In the observation period, total blinks observed for all subjects were 4,990 (1,414 normal, 3,576 dry eye). Of total blinks, 1,809 blinks (50.59\%) were partial and 1,767 (49.41\%) were complete blinks among dry-eye subjects versus $741(52.90 \%)$ partial and $673(47.60 \%)$ complete blinks among normal subjects. A comparison of these proportions demonstrated that they were not statistically different (see Table 1 for the full classification of blinks). However, the number of superextended blinks was found to be a significant ten times higher in dry-eye (mean 0.023 ) than normal (mean 0.002) subjects $(P=0.023)$.

Table I Proportions of blink types in dry-eye $(n=I 0)$ and normal $(n=I I)$ subjects

\begin{tabular}{|c|c|c|c|c|c|c|}
\hline \multirow{2}{*}{$\begin{array}{l}\text { Type of blink based } \\
\text { on lid closure }\end{array}$} & \multicolumn{6}{|c|}{ Blink types: proportions and odds ratios } \\
\hline & $\begin{array}{l}\text { Proportions, } \\
\text { dry eye } \\
(n=3,576)\end{array}$ & $\begin{array}{l}\text { Proportions, } \\
\text { normals } \\
(n=I, 4 \mid 4)\end{array}$ & $\begin{array}{l}\text { Ratio of } \\
\text { proportions, } \\
\text { dry eye/normals }\end{array}$ & $\begin{array}{l}\text { Ratio of odds, } \\
\text { dry eye/normals }\end{array}$ & $\begin{array}{l}95 \% \text { confidence } \\
\text { intervals for } \\
\text { odds ratio }\end{array}$ & $\begin{array}{l}P \text {-value for } \\
\text { equal odds }\end{array}$ \\
\hline $25 \%$ blinks & 0.026 & 0.032 & 0.825 & 0.821 & $(0.22,3.05)$ & 0.768 \\
\hline $50 \%$ blinks & 0.199 & 0.236 & 0.843 & 0.803 & $(0.33,1.93)$ & 0.625 \\
\hline $75 \%$ blinks & 0.349 & 0.331 & 1.057 & 1.087 & $(0.58,2.04)$ & 0.795 \\
\hline $\begin{array}{l}\text { All lid closures } \\
(>0 \text { second in duration) }\end{array}$ & 0.383 & 0.368 & $1.04 \mid$ & 1.066 & $(0.43,2.62)$ & 0.889 \\
\hline $\begin{array}{l}\text { Extended lid closures } \\
(>0.1 \text { second in duration })\end{array}$ & 0.015 & 0.032 & 0.463 & 0.455 & $(0.14,1.44)$ & 0.179 \\
\hline $\begin{array}{l}\text { Superextended lid closures } \\
(>0.5 \text { second in duration) }\end{array}$ & 0.023 & 0.002 & 10.029 & 10.242 & $(1.38,76.3)$ & 0.023 \\
\hline
\end{tabular}

Notes: Data were fitted to repeated-measurement logistic models estimated by generalized estimating equation methods. Dry-eye and normal groups were compared via odds ratios. Odds-ratio estimates, $95 \%$ confidence intervals, and P-values for the two-sided test of equal odds are presented. Group proportions and their ratios are also presented. Statistically significant $(P<0.05)$ differences between groups are highlighted in bold. 


\section{Blink rates}

With regard to all six types of blinks, the mean blink rate was 2.17 times higher in dry eyes than normals $(P<0.001): 28.55$ blinks/minute in dry-eye and 13.21 blinks/ minute in normal subjects. Similarly, the incidence of full lid closures was 2.3 times higher in dry-eye than normal subjects (14.12 and 6.11, respectively; $P=0.035$ ). While the incidence of extended blinks was not different, the incidence of superextended blinks was 8.22 times higher in dry-eye than normal subjects $(0.217$ versus 0.026 , respectively; $P=0.008)$. These data with the corresponding statistics can be found in Table 2.

\section{Mean duration of full lid closures}

The mean duration of each lid closure was then determined per blink type. Dry-eye subjects had seven times the mean duration of all categories of full closures of normal subjects $(0.565$ versus 0.080 seconds, respectively; $P<0.001)$. The mean duration of all extended blinks of $>0.1$ second (2.459 versus 0.575 , respectively; $P=0.003)$, and mean duration of all superextended blinks of $>0.5$ second (7.134 versus 1.589 , respectively; $P<0.001$ ) were also significantly four times longer in dry-eye versus normal subjects. These data are reported in Table 3.

\section{Lid-contact rates}

The concept of mean duration/blink was then extended to contact rate. The mean lid-closure time per type of full closure was divided by the subject's total observation time, and then standardized per minute. The contact rate for all full lid closures was 6.4 times longer in dry-eye $(0.045$ versus 0.007 , $P<0.001)$ than normal subjects, ie, dry-eye subjects spent $4.5 \%$ of a minute with their eyes closed, while normal subjects spent $0.7 \%$ of a minute with their eyes closed (see Table 3 ).
This indicated that for any given number of blinks, dry-eye subjects were keeping their lids closed significantly longer than normal subjects.

\section{Secondary analysis}

Several blinks (seven of 4,990) were observed to have lid-contact times of greater than or equal to 10 seconds. These were considered possible microsleeps, a phenomenon different even from superextended blinks of 0.5 seconds or more in duration. The data were reanalyzed without these possible microsleeps to determine if significantly prolonged times were still present. Dry-eye subjects were still 6.6 times more likely than normals to exhibit superextended blinks with a duration between 0.5 and 10 seconds ( $1.5 \%$ versus $0.2 \%$ of total respective blinks, $P=0.05$ ). All findings were still highly statistically significant: the mean duration of blink within each category was significantly greater in dry-eye versus normal subjects $(P$-values from 0.032 to $<0.001$ ), and mean lid-contact times were significantly longer in dry-eye versus normal subjects $(P \leq 0.001)$.

A total of ten squeeze blinks were noted in three dry-eye subjects and no normal subjects. Blinks per subject were two, three, and five. This level of incidence was too low for meaningful statistical analysis.

\section{Discussion}

In our continuing efforts to study blink phenomena, we have in the present investigation defined a new end point that showed marked differences between dry-eye and normal subjects: lid-contact time. In previous exploratory studies, we focused first on blink rates, or their reciprocal, IBIs, and the ability to use statistical characteristics of these time-series data to differentiate dry-eye and normal subjects. ${ }^{16}$ We then began

Table 2 Mean blink rates for all blinks (or incidence) of each of the full lid-closure blink types. Note that the incidence of extended and superextended closures decreases incrementally because the percentage of these blinks to total blinks is very low

\begin{tabular}{|c|c|c|c|c|c|}
\hline Mean blink rate & $\begin{array}{l}\text { Dry eye } \\
(n=I I)\end{array}$ & $\begin{array}{l}\text { Normal } \\
(n=10)\end{array}$ & $\begin{array}{l}\text { Risk ratio, dry } \\
\text { eye/normal }\end{array}$ & $\begin{array}{l}95 \% \text { confidence } \\
\text { intervals for odds ratio }\end{array}$ & $\begin{array}{l}P \text {-value } \\
\text { for equal odds }\end{array}$ \\
\hline $\begin{array}{l}\text { All full and partial blinks } \\
\text { (all } 6 \text { types) }\end{array}$ & 28.55 & 13.21 & 2.16 & $(I .4 I, 3.3 I)$ & $<0.001$ \\
\hline $\begin{array}{l}\text { All full lid closures } \\
\text { ( }>0 \text { second in duration) }\end{array}$ & 14.12 & 6.11 & 2.31 & $(1.06,5.04)$ & 0.035 \\
\hline $\begin{array}{l}\text { Extended lid closures } \\
(>0.1 \text { second in duration) }\end{array}$ & 0.548 & 0.509 & 1.078 & $(0.364,3.193)$ & 0.892 \\
\hline $\begin{array}{l}\text { Superextended lid closures } \\
(>0.5 \text { second in duration) }\end{array}$ & 0.217 & 0.026 & 8.223 & $(1.729,39.097)$ & 0.008 \\
\hline
\end{tabular}

Notes: Data were fitted to repeated-measurement logistic models estimated by generalized estimating equation methods. Dry-eye and normal groups were compared via odds ratios. Odds-ratio estimates, $95 \%$ confidence intervals, and $P$-values for the two-sided test of equal odds are presented. Group proportions and their ratios are also presented. Statistically significant $(P<0.05)$ differences between groups are highlighted in bold. 
Table 3 Mean lid-closure durations per type of blink for dry-eye and normal subjects, and duration standardized per minute to provide a mean contact rate per type of blink

\begin{tabular}{|c|c|c|c|c|c|c|}
\hline Full-blink categories & $\begin{array}{l}\text { Number of subjects } \\
\text { who experienced } \\
\text { this type of blink }\end{array}$ & $\begin{array}{l}\text { Dry-eye } \\
\text { subjects } \\
(n=I I)\end{array}$ & $\begin{array}{l}\text { Normal } \\
\text { subjects } \\
(n=10)\end{array}$ & $\begin{array}{l}\text { Risk ratio, } \\
\text { dry eye/ } \\
\text { normals }\end{array}$ & $\begin{array}{l}95 \% \text { confidence } \\
\text { intervals for } \\
\text { odds ratio }\end{array}$ & $\begin{array}{l}P \text {-value } \\
\text { for equal } \\
\text { odds }\end{array}$ \\
\hline \multicolumn{7}{|c|}{ Mean duration of lid closure/blink (seconds) } \\
\hline $\begin{array}{l}\text { All full lid closures } \\
\text { ( }>0 \text { second in duration) }\end{array}$ & $\begin{array}{l}21 \\
\text { II dry eye } \\
10 \text { normals }\end{array}$ & 0.565 & 0.080 & 7.074 & $(2.46,20.33)$ & $<\mathbf{0 . 0 0 I}$ \\
\hline $\begin{array}{l}\text { Extended lid closures } \\
(>0.1 \text { second in duration })\end{array}$ & $\begin{array}{l}15 \\
7 \text { dry eye } \\
7 \text { normals }\end{array}$ & 2.459 & 0.575 & 4.274 & $(1.65,11.07)$ & 0.003 \\
\hline $\begin{array}{l}\text { Superextended lid closures } \\
(>0.5 \text { second in duration) }\end{array}$ & $\begin{array}{l}6 \\
3 \text { dry eye } \\
3 \text { normals }\end{array}$ & 7.134 & 1.589 & 4.490 & $(3.28,6.15)$ & $<\mathbf{0 . 0 0 I}$ \\
\hline \multicolumn{7}{|l|}{ Contact rate* } \\
\hline $\begin{array}{l}\text { All full blinks: contact } \\
\text { time }>0 \text { seconds }\end{array}$ & $\begin{array}{l}21 \\
\text { II dry eye } \\
\text { I0 normals }\end{array}$ & $4.5 \%$ & $0.7 \%$ & 6.377 & $(2.47,16.46)$ & $<\mathbf{0 . 0 0 1}$ \\
\hline $\begin{array}{l}\text { Extended blinks: contact } \\
\text { time }>0.1 \text { seconds }\end{array}$ & $\begin{array}{l}15 \\
7 \text { dry eye } \\
7 \text { normals }\end{array}$ & $4.7 \%$ & $0.4 \%$ & 12.572 & $(3.35,47.26)$ & $<0.001$ \\
\hline $\begin{array}{l}\text { Superextended blinks: } \\
\text { contact time }>0.5 \text { second }\end{array}$ & $\begin{array}{l}6 \\
3 \text { dry eye } \\
3 \text { normals }\end{array}$ & $10.3 \%$ & $0.2 \%$ & 44.793 & $(17.73,113.16)$ & $<\mathbf{0 . 0 0 I}$ \\
\hline
\end{tabular}

Notes: Data were fitted to repeated-measurement logistic models estimated by generalized estimating equation methods. Dry-eye and normal groups were compared via odds ratios. Odds-ratio estimates, $95 \%$ confidence intervals, and $P$-values for the two-sided test of equal odds are presented. Group proportions and their ratios are also presented. Statistically significant $(P<0.05)$ differences between groups are highlighted in bold. *Percentages $=$ total contact time/total observed time $($ standardized per minute).

exploring the duration of blinks, finding that abnormally long lid closures appear to occur with greater frequency in dry-eye subjects, and that the IBIs surrounding these long lid closures are modified only in dry-eye subjects. ${ }^{17}$ We turned our attention in this study to a complete categorization of blinks into their six types: three partial types $(25 \%, 50 \%$, and $75 \%)$, all full blinks with complete lid closure, all full extended blinks with greater than 0.1 second lid closure, and superextended blinks of greater than 0.5 second in duration, distilling into ever-narrowing categories the average total time the subjects' eyes were closed. Since the category of all full closures incorporated reflex blinking, which is known to involve a different underlying neural substrate than the conscious lid closures isolated under the categories of extended and superextended closures, attention was focused on the incidence and duration of the latter as a clearly different phenomena.

In a final analysis, we also excluded seven possible "microsleeps" of greater than 10 seconds in duration from the analysis to assure that these were not accounting for the significant effects observed. Although microsleeps were originally interpreted as an actual electroencephalogram-defined sleep state, such long-duration lid closures have also been observed in contexts that do not always seem to correspond to actual sleep, and have been referred to as "behavioral microsleeps". ${ }^{5}$ These superextended lid closures were possibly more a conscious resting of the eyes during the observation period. However, even without these seven blinks, all results were consistent and significant.

The mean total duration of lid closure per type of blink appears to be the most clinically meaningful end point that we found, showing dramatic differences between dry eye and normal subjects. The finding of $4.5 \%$ versus less than $1 \%$ of time with lids closed in dry-eye and normal subjects, respectively, ascribes to the negative consequences of dry eye on daily activities and visual function that are well noted on many quality of life-based studies. ${ }^{13,15}$ This end point more clearly reflects the greater necessity of dry-eye patients to "refresh" the tear film during visual tasking than a simple blink rate or IBI, in which the mean total time of lid closure is not considered.

The present study corroborates a recent similar investigation by Pult et al who determined the relationship of blink to dry-eye symptoms and lid parallel conjunctival folds (LIPCOFs), and by qualitatively classifying blink patterns by almost-complete, incomplete, and complete. They showed a significant correlation of almost-complete blinks with LIPCOFs but not with the standard questionnaire for dry-eye 
symptoms: the Ocular Surface Disease Index. ${ }^{30}$ Our study provides a quantification of this blink anomaly by determining actual mean lid-contact time per type of blink and the differences noted between dry-eye and normal subjects. The finding that dry-eye subjects have their eyes closed for longer than normals given any type of lid closure provides one explanation for impaired visual function. We believe these results are of interest, although it is important to acknowledge that we are limited by a very small sample size and our control group was not age- or sex-matched. We are presently developing these blink end points further within the context of important visual function tasks, such as reading.

\section{Disclosure}

The authors report no conflicts of interest in this work.

\section{References}

1. Abelson MB, Holly FJ. A tentative mechanism for inferior punctate keratopathy. Am J Ophthalmol. 1977;83:866-869.

2. Doane MG. Interactions of eyelids and tears in corneal wetting and the dynamics of the normal human eyeblink. Am J Ophthalmol. 1980; 89:507-516.

3. Doane MG. Blinking and the mechanics of the lacrimal drainage system. Ophthalmology. 1981;88:844-851.

4. Stern JA, Walrath LC, Goldstein R. The endogenous eyeblink. Psychophysiology. 1984;21:22-33.

5. Peiris MT, Jones RD, Davidson PR, Carroll GJ, Bones PJ. Frequent lapses of responsiveness during an extended visuomotor tracking task in non-sleep-deprived subjects. J Sleep Res. 2006;15:291-300.

6. Himebaugh NL, Begley CG, Bradley A, Wilkinson JA. Blinking and tear break-up during four visual tasks. Optom Vis Sci. 2009;86:E106-E114.

7. Cardona G, García C, Serés C, Vilaseca M, Gispets J. Blink rate, blink amplitude, and tear film integrity during dynamic visual display terminal tasks. Curr Eye Res. 2011;36:190-197.

8. Freudenthaler N, Neuf H, Kadner G, Schlote T. Characteristics of spontaneous eyeblink activity during video display terminal use in healthy volunteers. Graefes Arch Clin Exp Ophthalmol. 2003;241:914-920.

9. Stern JA. Blink rate: a possible measure of fatigue. Hum Factors. 1994; 36:285-297.

10. Schleicher R, Galley N, Briest S, Galley L. Blinks and saccades as indicators of fatigue in sleepiness warnings: looking tired? Ergonomics. 2008;51:982-1010.

11. Häkkänen H, Summala H, Partinen M, Tiihonen M, Silvo J. Blink duration as an indicator of driver sleepiness in professional bus drivers. Sleep. 1999;22:798-802.

12. Johns MW, Tucker A, Chapman R, Crowley K, Micheal N. Monitoring eye and eyelid movements by infrared reflectance oculography to measure drowsiness in drivers. Somnologie. 2007;11:234-242.

Clinical Ophthalmology

\section{Publish your work in this journal}

Clinical Ophthalmology is an international, peer-reviewed journal covering all subspecialties within ophthalmology. Key topics include: Optometry; Visual science; Pharmacology and drug therapy in eye diseases; Basic Sciences; Primary and Secondary eye care; Patient Safety and Quality of Care Improvements. This journal is indexed on Submit your manuscript here: http://www.dovepress.com/clinical-ophthalmology-journal
13. Toda I, Fujishima H, Tsubota K. Ocular fatigue is the major symptom of dry eye. Acta Ophthalmol. 1993;71:347-352.

14. Torkildsen G. The effects of lubricant eye drops on visual function as measured by the Interblink Interval Visual Acuity Decay Test. Clin Ophthalmol. 2009;3:501-506.

15. Miljanovic B, Dana R, Sullivan DA, Schaumberg DA. Impact of dry eye syndrome on vision-related quality of life. Am J Ophthalmol. 2007; 143:409-415.

16. Johnston PR, Rodriguez J, Lane KJ, Ousler G, Abelson MB. The interblink interval in normal and dry eye subjects. Clin Ophthalmol. 2013;7:253-259.

17. Rodriguez JD, Ousler GW 3rd, Johnston PR, Lanke K, Abelson MB. Investigation of extended blinks and interblink intervals in subjects with and without dry eye. Clin Ophthalmol. 2013;7:337-342.

18. Tsubota K, Hato S, Okusawa Y, Egami F, Ohtisuki T, Nakamori K. Quantitative videographic analysis of blinking in normal subjects and patients with dry eye. Arch Ophthalmol. 1996;114:715-720.

19. Nakamori K, Odawara M, Nakajima T, Mizutani T, Tsubota K. Blinking is controlled primarily by ocular surface conditions. Am J Ophthalmol. 1997;124:24-30.

20. Schlote T, Kadner G, Freudenthaler N. Marked reduction and distinct patterns of eye blinking in patients with moderately dry eyes during video display terminal use. Graefes Arch Clin Exp Ophthalmol. 2004; 242:306-312.

21. Alex A, Edwards A, Hays JD, et al. Factors predicting the ocular response to desiccating environmental stress. Invest Ophthalmol Vis Sci. 2013;54:3325-3332.

22. Miura DL, Hazabassanov RM, Yamasato CK, Bandeira e Silva F, Godinho CJ, Gomes JA. Effect of a light-emitting timer device on the blink rate of non-dry eye individuals and dry eye patients. $\mathrm{Br} J$ Ophthalmol. 2013;97:965-967.

23. Leigh RJ, Zee DS. The Neurology of Eye Movements. New York: Oxford University Press; 2006.

24. Powers AS, Coburn-Litvak P, Evinger C. Conditioned eyelid movement is not a blink. J Neurophysiol. 2010;103:641-647.

25. Harrison Y, Horne JA. Occurrence of 'microsleeps' during day time sleep onset in normal subjects. Electroencephalogr Clin Neurophysiol. 1996;98:411-416.

26. Cruz AA, Garcia DM, Pinto CT, Cechetti SP. Spontaneous eyeblink activity. Ocul Surf. 2011;9:29-41.

27. Pult H, Riede-Pult BH, Murphy PJ. A new perspective on spontaneous blinks. Ophthalmology. 2013;120:1086-1091.

28. Korb DR, Baron DF, Herman JD, et al. Tear film lipid layer thickness as a function of blinking. Cornea. 1994;13:354-359.

29. Benedetto DA, Clinch TE, Laibson PR. In vivo observation of tear dynamics using fluorophotometry. Arch Ophthalmol. 1984;102: 410-412.

30. Pult H, Riede-Pult BH, Murphy PJ. The relation between blinking and conjunctival folds and dry eye symptoms. Optom Vis Sci. 2013;90: 1034-1039.

\section{Dovepress}

PubMed Central and CAS, and is the official journal of The Society of Clinical Ophthalmology (SCO). The manuscript management system is completely online and includes a very quick and fair peer-review system, which is all easy to use. Visit http://www.dovepress.com/ testimonials.php to read real quotes from published authors. 